\title{
High Strain Rate Superplasticity in Al-Zn-Mg-Based Alloy: Microstructural Design, Deformation Behavior, and Modeling
}

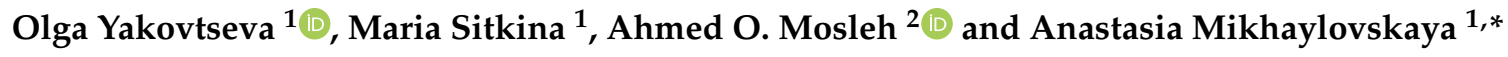 \\ 1 Department of Physical Metallurgy of Non-Ferrous Metals, National University of Science and \\ Technology MISiS, Moscow 119049, Russian; yakovtseva.oa@misis.ru (O.Y.); sitkina.m@misis.ru (M.S.) \\ 2 Mechanical Engineering Department, Shoubra Faculty of Engineering, Benha University, \\ 108 Shoubra St., P.O., Cairo 11629, Egypt; ahmed.omar@feng.bu.edu.eg \\ * Correspondence: mihaylovskaya@misis.ru; Tel.: +7-(495)-638-44-80
}

Received: 10 April 2020; Accepted: 27 April 2020; Published: 1 May 2020

\begin{abstract}
Increasing the strain rate at superplastic forming is a challenging technical and economic task of aluminum forming manufacturing. New aluminum sheets exhibiting high strain rate superplasticity at strain rates above $0.01 \mathrm{~s}^{-1}$ are required. This study describes the microstructure and the superplasticity properties of a new high-strength $\mathrm{Al}-\mathrm{Zn}-\mathrm{Mg}$-based alloy processed by a simple thermomechanical treatment including hot and cold rolling. The new alloy contains $\mathrm{Ni}$ to form $\mathrm{Al}_{3} \mathrm{Ni}$ coarse particles and minor additions of $\operatorname{Zr}(0.19 \mathrm{wt} . \%)$ and Sc $(0.06 \mathrm{wt} . \%)$ to form nanoprecipitates of the $\mathrm{L1}_{2}-\mathrm{Al}_{3}(\mathrm{Sc}, \mathrm{Zr})$ phase. The design of chemical and phase compositions of the alloy provides superplasticity with an elongation of $600-800 \%$ in a strain rate range of 0.01 to $0.6 / \mathrm{s}$ and residual cavitation less than $2 \%$. A mean elongation-to-failure of $400 \%$ is observed at an extremely high constant strain rate of $1 \mathrm{~s}^{-1}$. The strain-induced evolution of the grain and dislocation structures as well as the $\mathrm{L}_{2}$ precipitates at superplastic deformation is studied. The dynamic recrystallization at superplastic deformation is confirmed. The superplastic flow behavior of the proposed alloy is modeled via a mathematical Arrhenius-type constitutive model and an artificial neural network model. Both models exhibit good predictability at low and high strain rates of superplastic deformation.
\end{abstract}

Keywords: aluminum alloy; superplasticity; dynamic recrystallization; microstructural study; dislocation structure; precipitate free zone; mathematical modeling

\section{Introduction}

The effect of superplasticity was first described in the last century, and the nature of the phenomenon is almost clear today [1-4]. There are many works that describe this phenomenon and its feature, mechanism, and applications [5-7]. Owing to their fine and stable to growth grain structure and related high strain rate sensitivity of the flow stress, superplastic metallic materials demonstrate a quasi-uniform deformation with elongation-to-failure from several hundred to several thousand percent [8]. The phenomenon is used for superplastic forming (SPF), which is an effective technique of a low-volume production of complex-shape parts $[9,10]$. SPF allows obtaining high-quality products with very precise matrix repeatability in one processing operation using a gas in the forming process $[3,10]$. SPF is commercially mostly applied for aluminum- and titanium-based alloys. Several conventional superplastic aluminum alloys are manufactured, but most of them exhibit superplasticity at extremely low strain rates $\leq 0.002 \mathrm{~s}^{-1}[11,12]$. Due to their low cost and excellent corrosion resistance, Al-Mg-based alloys are the most common ones $[13,14]$. Their main disadvantage is low yield strength, which is insufficient for many technical requirements [15,16]. Most of the high-strength Al-Zn-Mg-Cu-based 
alloys have two critical issues: (1) large residual cavitation [17-19] and (2) an extremely low strain rate $\left(10^{-4} \mathrm{~s}^{-1}\right)$ [20-23]. The development of aluminum alloys with high strain rate superplasticity is a challenging task [24-26]. The desired SPF strain rates that help to increase SPF productivity are more than $10^{-2} \mathrm{~s}^{-1}[27,28]$. The strain rate above $10^{-1} \mathrm{~s}^{-1}$ makes the SPF method applicable for mass production [29].

Owing to their grain size sensitivity, the superplastic properties can be significantly improved by optimization of thermomechanical treatments [30,31] (including severe plastic deformation [32-34]) and chemical composition modification. Both methods focus on a grain refinement effect. The standard processing approach to obtain a fine-grained structure is cold rolling and subsequent recrystallization $[2,6,12,35]$. For this approach, the presence of the second phase particles of various dispersions is an important grain refinement criterion [36,37]. The coarse particles increase the nucleation rate during recrystallization due to the particle stimulated nucleation (PSN) effect [36-40]; fine particles inhibit a grain growth at annealing and elevated-temperature deformation due to the Zener pinning effect $[37,41,42]$.

The purpose of this study is to develop a novel alloy capable of high-strain rate superplasticity and demonstrate low residual cavitation. The novel alloy provides a forming cycle reduction and expands the SPF application. This study describes the microstructure and the superplastic properties of a new high-strength Al-Zn-Mg-based alloy. The alloy is designed based on the principle of optimal microstructural heterogeneity [6,43]. An addition of nickel helps to create coarse particles of crystallization origin for PSN [44-48], and Sc and Zr provide the formation of nanoprecipitates for grain size stabilization via Zener pinning [48-51]. To minimize the alloy cost, the Sc content is chosen on the extremely low level of $0.06 \mathrm{wt} . \%$. Notably, the sheet was processed by a simple thermomechanical treatment, including hot and cold rolling, which is applicable and inexpensive for manufacture. The optimal deformation regime including temperature, strain rate, and strain ranges should be found. The stress-strain data are required to develop pressure-time forming cycles and to simulate the superplastic forming process $[10,52,53]$. Mathematical models help to identify the correct SPF processing parameters and to reduce the number of experiments and the processing time $[54,55]$.

The Arrhenius-type constitutive model is a phenomenological model that is generally utilized in modeling elevated temperature deformation $[56,57]$. This model provides very good predictability of the hot deformation behavior of various metallic materials [58-61]. The artificial neural network (ANN) exhibits an essentially different approach to simulate the flow behavior of metallic materials $[62,63]$. The ANN differs from statistical or numerical methods and can be used for modeling various processes without any physical principals. To minimize the variation between the inputs and the targets is the main idea of the ANN analysis. Despite the rising popularity of artificial neural networks, one should exercise caution when using them for predicting the mechanical behavior of materials. Thus, here we compare the predictability of the mechanical behavior of the studied alloy using the ANN and the classical approach based on the constitutive equations of the Arrhenius type. The development of mathematical models of superplastic deformation behavior of the studied alloy based on both Arrhenius-type constitutive hyperbolic equation (ACE) and ANN is the second important purpose of the study.

\section{Materials and Methods}

\subsection{Preparation}

The studied alloy with a chemical composition of Al-3.8\% $\mathrm{Zn}-4.2 \% \mathrm{Mg}-3.6 \% \mathrm{Ni}-0.19 \% \mathrm{Zr}-0.06 \% \mathrm{Sc}$ (wt.\%) was made from technically pure metals $99.85 \mathrm{wt} \% \mathrm{Al}, 99.92 \mathrm{wt} . \% \mathrm{Zn}$, and $99.95 \mathrm{wt} . \% \mathrm{Mg}$ and master alloys of Al-18 wt. $\% \mathrm{Ni}, \mathrm{Al}-3.5 \mathrm{wt} . \% \mathrm{Zr}$, and Al-2wt.\%Sc. The alloy was melted in a Nabertherm S3 laboratory electric furnace in a graphite-fireclay crucible. The casting temperature was about $770{ }^{\circ} \mathrm{C}$. The ingot obtained by casting in a water-cooled copper mold with internal dimensions of $100 \times 40 \times 20 \mathrm{~mm}^{3}$ provided a solidification rate of $\sim 15 \mathrm{~K} / \mathrm{s}$. Homogenization annealing was performed 
in three steps at temperatures of $360 \pm 2{ }^{\circ} \mathrm{C}$ for $6 \mathrm{~h}, 450 \pm 2{ }^{\circ} \mathrm{C}$ for $3 \mathrm{~h}$, and $500 \pm 2{ }^{\circ} \mathrm{C}$ for $2 \mathrm{~h}$ in a Nabertherm N30/65A furnace with air convection. The first annealing step aimed to precipitate the coherent $\mathrm{Al}_{3}(\mathrm{Sc}, \mathrm{Zr})$ nanoscale dispersoids, and the second one aimed to dissolve the nonequilibrium $\mathrm{T}\left(\mathrm{Al}_{2} \mathrm{Mg}_{3} \mathrm{Zn}_{3}\right)$ phase. The third step provided the spheroidization and fragmentation of the $\mathrm{Al}_{3} \mathrm{Ni}$ particles as well as the elimination of dendrite liquation of the aluminum solid solution. Hot rolling performed at $420 \pm 10^{\circ} \mathrm{C}$ to a thickness of $3 \mathrm{~mm}$ followed rolling at room temperature to process a sheet thickness of $1 \mathrm{~mm}$. The incipient melting/solidus temperature $\left(\mathrm{T}_{\text {i.m. }}\right)$ of the alloy was $552{ }^{\circ} \mathrm{C}$; it was determined by the differential thermal analysis using a Setaram Labsys DSC 1600 calorimeter with a cooling rate of $5 \mathrm{~K} / \mathrm{s}$.

\subsection{Microstructural Analyses}

The microstructure and the local chemical composition were controlled using a TESCAN Vega 3 LMH scanning electron microscope (SEM, Tescan Brno s.r.o., Kohoutovice, Czech Republic) with an X-Max 80 energy-dispersive detector. The SEM imaging was conducted using secondary electron and backscattered electron scanning regimes. An Axiovert 200 MMat light/optical microscope (LM, Carl Zeiss Oberkochen, Germany) was used to analyze the grain structure in polarized light. The specimens were cut from the upper and lower parts of the ingot and from several parts of the rolled sheet. The specimens were prepared by mechanical grinding by a SiC paper and the final polishing with a colloidal silica suspension using a Struers LaboPol machine (Struers ApS, Ballerup, Denmark). The grain structure was analyzed after an anodic oxidation in a 10\% fluoroboric acid water solution. The volume fractions, the size, the shape of the particles, and the cavity volume fraction were determined via analyses of 7-8 micrographs using an AxioVision 4.5 software (Carl Zeiss Oberkochen, Germany).

The dispersoid parameters and the dislocation structure were examined using a JEOL JEM-2000EX transmission electron microscope (TEM, Tokyo, Japan). The specimens for TEM were discs of $3 \mathrm{~mm}$ in diameter mechanically pre-ground to a thickness of $0.22 \mathrm{~mm}$. The finish step of the TEM-specimens preparation was electropolishing in a Struers TenuPol-5 (Struers ApS, Ballerup, Denmark) device using a $70 \% \mathrm{CH}_{3} \mathrm{OH}+30 \% \mathrm{HNO}_{3}$ electrolyte at a temperature of $253 \mathrm{~K}$ and a polishing voltage of $19.5 \mathrm{~V}$.

\subsection{Superplastic Parameters}

The specimens for the elevated temperature tensile tests were cut along the rolling direction of the sheet; the gauge size had a length of $14 \mathrm{~mm}$ and a width of $6 \mathrm{~mm}$. The superplastic parameters were determined via a step-by-step change in the strain rate tests and constant strain rate tests. The strain rate was maintained constant because the traverse speed increases proportionally as the specimen length increases. The tests were performed in an argon atmosphere on a Walter Bay LFM-100 testing machine with Dion-Pro software (Walter + Bai AG, Löhningen, Switzerland), which allowed programing the traverse motion during the experiment. The step-by-step increase strain rate tests were done in a temperature range of 400 to $520^{\circ} \mathrm{C}$ after pre-straining to e $=0.69(100 \%)$ at a low strain rate of $0.002 \mathrm{~s}^{-1}$; this strain is required to the formation of a near-recrystallized grain structure. The m-index vs. strain rate curves were achieved by differentiation of the stress-strain rate logarithmic curves. The constant strain rate tests were performed in a strain rate range of 0.002 to $1 \mathrm{~s}^{-1}$ and a temperature range of 400 to $520^{\circ} \mathrm{C}$.

\subsection{Modeling}

The experimental data obtained by the constant strain rate tests at different deformation temperatures and strain rates were used to construct the Arrhenius-type constitutive hyperbolic equation (ACE) and the artificial neural network (ANN) models [64]. The sequences of building each model were described in detail in the previous works $[65,66]$. The performance of the constructed 
models was assessed by calculating the correlation coefficient (R) (Equation (1)), the root mean square error (RMSE) (Equation (2)), and the average absolute relative error (AARE) (Equation (3)) [67,68].

$$
\begin{gathered}
R=\frac{\sum_{i=1}^{N}\left(E_{i}-\bar{E}\right)\left(P_{i}-\bar{P}\right)}{\sqrt{\sum_{i=1}^{N}\left(E_{i}-\bar{E}\right)^{2} \sum_{i=1}^{N}\left(P_{i}-\bar{P}\right)^{2}}} \\
R M S E=\sqrt{\frac{1}{N} \sum_{i=1}^{N}\left(E_{i}-P_{i}\right)^{2}} \\
\text { AARE }=\frac{1}{N} \sum_{i=1}^{N}\left|\frac{E_{i}-P_{i}}{E_{i}}\right|
\end{gathered}
$$

where

$E_{i}$, and $P_{i}$ are the experimental and modeled flow stress, respectively;

$\bar{E}$ and $\bar{P}$ are the mean values of the experimental and modeled flow stress, respectively; and

$N$ is the sample size.

The predictability of the constructed ACE and ANN models was evaluated by comparing the experimental results obtained at a temperature of $440{ }^{\circ} \mathrm{C}$ and a strain rate of $0.01 \mathrm{~s}^{-1}$ and $0.1 \mathrm{~s}^{-1}$ (these conditions were not included within the input conditions for constructing both models) with the predicted values from both models.

\section{Results and Discussion}

\subsection{Subsection}

The mean size of Al3Ni eutectic particles was $0.82 \pm 0.15 \mu \mathrm{m}$, the form factor of 0.92 and their fraction was $9 \pm 2 \%$ (Figure 1a). After annealing in a temperature range of 400 to $520{ }^{\circ} \mathrm{C}\left(0.86-0.96 \mathrm{~T}_{\mathrm{i} . \mathrm{m}}\right.$. $)$ for $30 \mathrm{~min}$, the grain structure consisted of the banded grains of a mean size $2.8 \pm 0.2 \mu \mathrm{m}$ (Figure $1 \mathrm{~b}$ ).
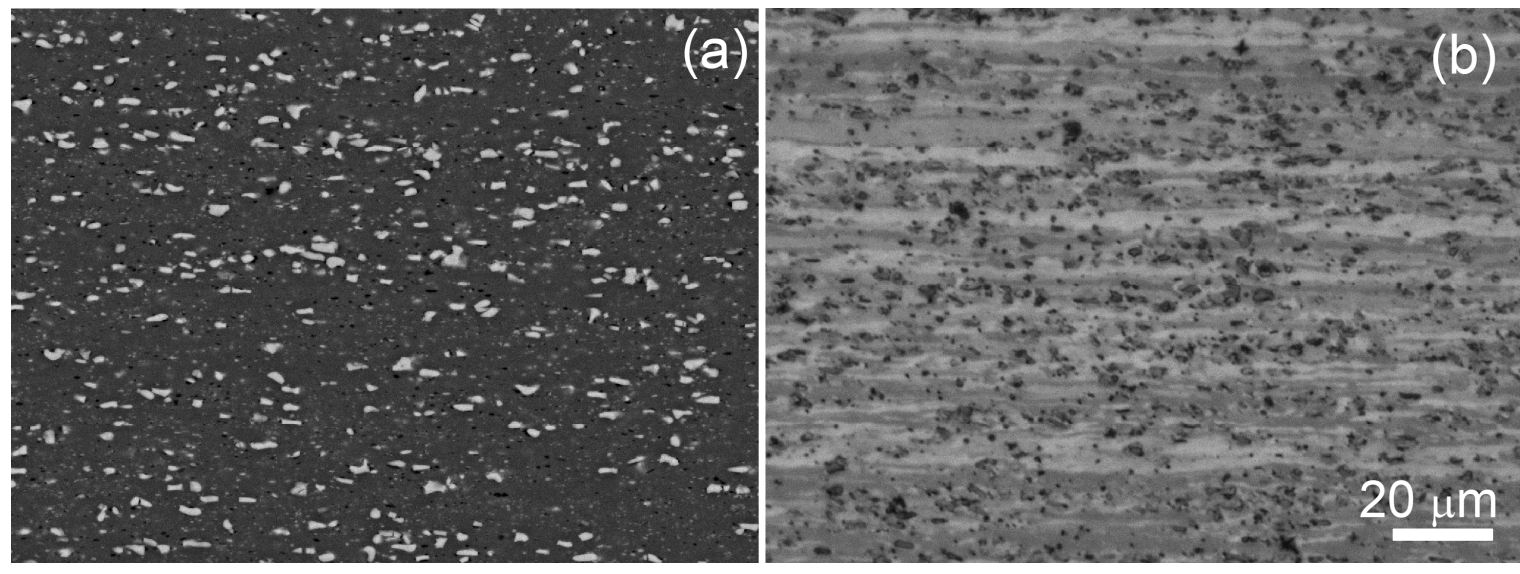

Figure 1. Initial microstructure after (a) cold rolling, SEM; (b) LM-image after annealing at a temperature of $520^{\circ} \mathrm{C}$ for $30 \mathrm{~min}$.

Figure 2a shows the stress-strain rate logarithmic curves that have a typical superplastic behavior sigmoidal shape that consists of three regions $[2,6,8,69]$. The second liner region corresponds to superplastic behavior [2,8]. In a temperature range of 440 to $520^{\circ} \mathrm{C}$, the maximum strain rate sensitivity $\mathrm{m}$-index ranged from 0.45 to 0.55 (Figure $2 \mathrm{~b}$ ). With decreasing the deformation temperature from 520 to $440{ }^{\circ} \mathrm{C}$, the maximum $\mathrm{m}$ decreased, while its strain rate position indicating an optimum strain rate value increased. The maximum optimum strain rate of $0.02 \mathrm{~s}^{-1}$ (maximum-m position) and the maximum elongation-to-failure of $854 \pm 21 \%$ during the constant strain rate tests (Figure 2c,d) were 
achieved at $440{ }^{\circ} \mathrm{C}$. The alloy exhibited a stable flow with an elongation of $700-800 \%$ at a constant strain rate of $0.02 \mathrm{~s}^{-1}$ in a temperature range of 440 to $520^{\circ} \mathrm{C}$ (Figure 2c), and the same elongation values at $440{ }^{\circ} \mathrm{C}$ in a constant strain rate range of 0.01 to $0.6 \mathrm{~s}^{-1}$ (Figure 2d). It is notable that the evidence of superplasticity with a mean elongation-to-failure of $402 \pm 28 \%$ was detected at an extremely high constant strain rate of $1 \mathrm{~s}^{-1}$. The near-superplastic behavior was observed at lower temperatures of $400-420^{\circ} \mathrm{C}$, but the maximum m-value reached only $0.32-0.37$, and a mean elongation-to-failure at a strain rate of $0.02 \mathrm{~s}^{-1}$ was $\leq 400 \%$.
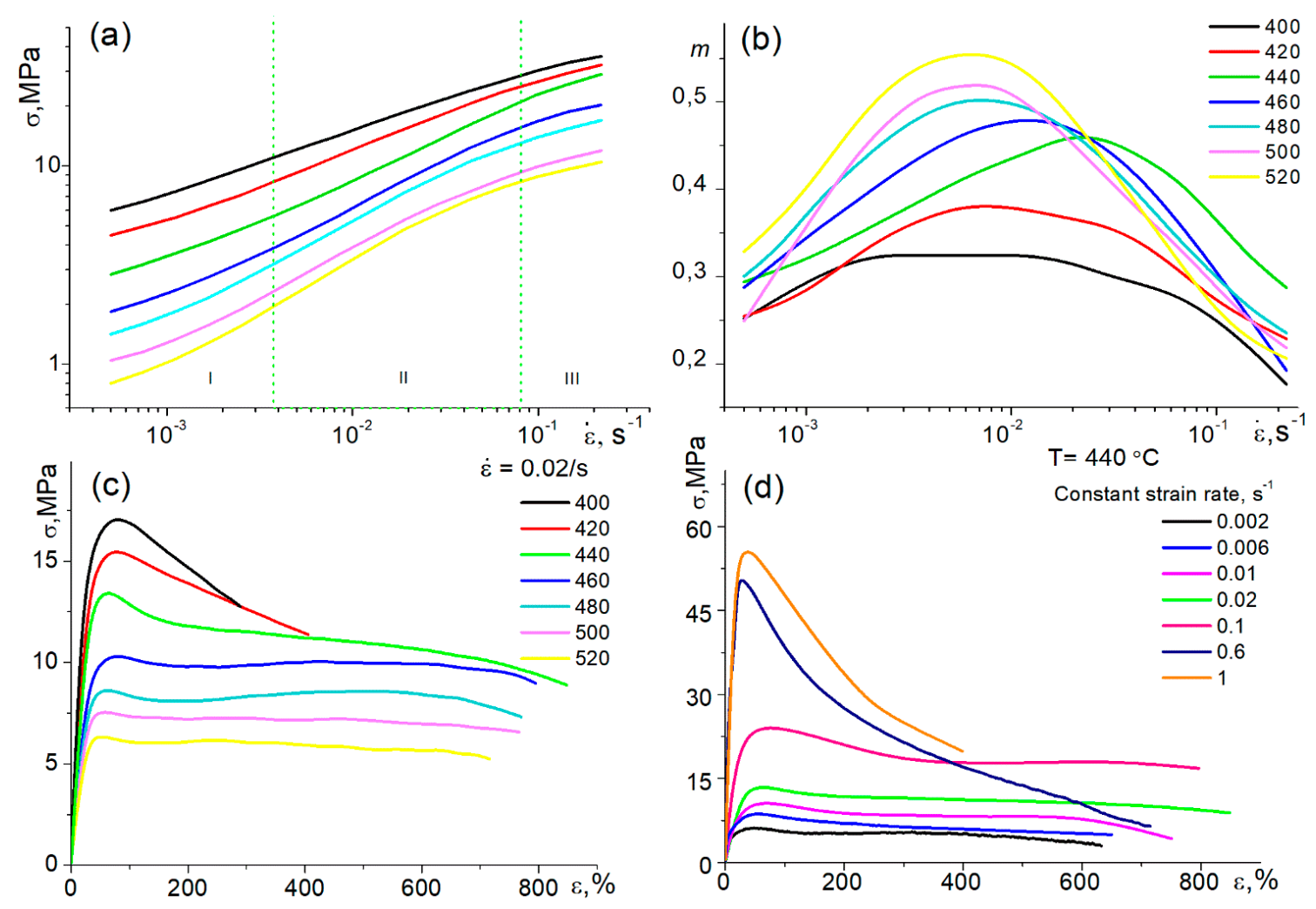

Figure 2. (a) Stress-strain rate logarithmic curves and (b) strain rate sensitivity $\mathrm{m}$-index-strain rate semilogarithmic curves in a temperature range of 400 to $520{ }^{\circ} \mathrm{C}$ (the samples were pre-deformed to 0.69 at a constant strain rate of $0.002 \mathrm{~s}^{-1}$ at each temperature); (c) stress-strain curves at a range of 400 to $520{ }^{\circ} \mathrm{C}$ and a constant strain rate $0.02 \mathrm{~s}^{-1}$; (d) stress-strain curves at a temperature of $440{ }^{\circ} \mathrm{C}$ and different strain rates.

Most of the stress-strain curves in Figure 2c,d can be divided into two main parts: (1) the peak stress at low strains of $\sim 30-50 \%$ with strain softening up to $100 \%(e=0.69)$ and $(2)$ the near-stable flow accompanied insignificant strain softening/hardening. At a temperature of $440{ }^{\circ} \mathrm{C}$ and a high strain rate of $0.1 \mathrm{~s}^{-1}$, softening occurred at a larger strain of $250 \%$. At a low temperature of $400-440{ }^{\circ} \mathrm{C}$ and strain rates of 0.6 and $1 \mathrm{~s}^{-1}$, the deformation was accompanied by softening up to-failure (see the red and black curves in Figure $2 c$ and the dark-blue and orange curves in Figure $2 d$ ). As the deformation was quasi-uniform, the strain rate was constant at testing, and the initial grain structure was unrecrystallized, such stress-strain behavior can be related to a dynamic recrystallization $[17,37,70]$. At lower temperatures and higher strain rates, the dynamic recrystallization needs larger strains and more time to complete, and prolonged strain softening was observed. The microstructural studies confirmed the transformation of the initial banded grains into equiaxed dynamically recrystallized ones (see the example of the microstructure of the samples deformed to failure at $420^{\circ} \mathrm{C}$ and $0.02 \mathrm{~s}^{-1}$ in Figure 3a). 

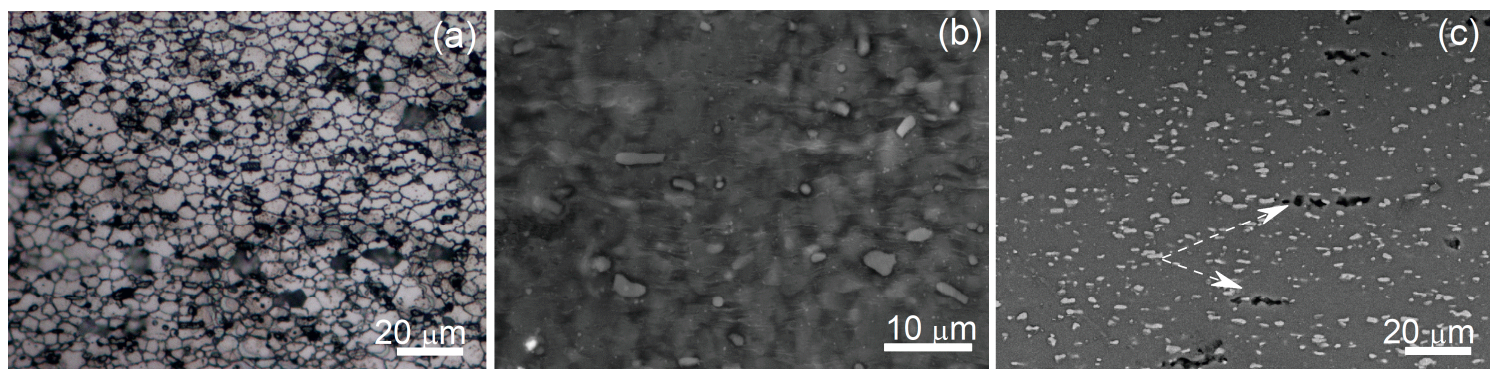

Figure 3. Microstructures after superplastic deformation: (a) LM image of the grain structure after failure at $420{ }^{\circ} \mathrm{C}$ and $0.02 \mathrm{~s}^{-1}$; (b) SEM image of the deformed at $0.02 \mathrm{~s}^{-1}$ and $440{ }^{\circ} \mathrm{C}$ to strain of 0.69 pre-polished surface; (c) SEM microstructure after failure at e $=2.2$ at a strain rate of $0.02 \mathrm{~s}^{-1}$ at $440{ }^{\circ} \mathrm{C}$; the white arrows indicate cavities; the tensile direction is horizontal.

The strain-induced microstructural evolution was carefully studied at a temperature of $440{ }^{\circ} \mathrm{C}$ and a strain rate of $0.02 \mathrm{~s}^{-1}$; those deformation conditions corresponded to the maximum strain rate sensitivity and the maximum elongation-to-failure. A typical superplastic deformation surface relief related to grain boundary sliding was revealed on the pre-polished sample deformed to 0.69 (Figure $3 \mathrm{~b}$ ). A high fraction of $60 \%$ of low-angle grain boundaries (LAGB, $2-15^{\circ}$ ) and a small fraction of $40 \%$ of high-angle grain boundaries (HAGB $\geq 15^{\circ}$ ) were observed before the start of superplastic deformation (Figure 4a). The LAGB fraction significantly decreased and the HAGB proportionally increased to $82 \%$ after 0.69 of strain (Figure 4 b), and to $90 \%$ after 2.2 of strain (Figure $4 c$ ). Thus, the strain softening at the beginning of the deformation is explained by the dynamic recrystallization process, which was stimulated by PSN in the presence of $\mathrm{Al}_{3} \mathrm{Ni}$ particles $[45,46]$. There was no significant grain growth at deformation; the mean grain size was $1.9 \pm 0.4 \mu \mathrm{m}$ after a strain of 0.69 and $2.4 \pm 0.3 \mu \mathrm{m}$ after failure at a strain of 2.2 (Figure 4). Therefore, a fine-grained structure is formed at superplastic deformation and the grains demonstrate increased size stability to dynamic growth.
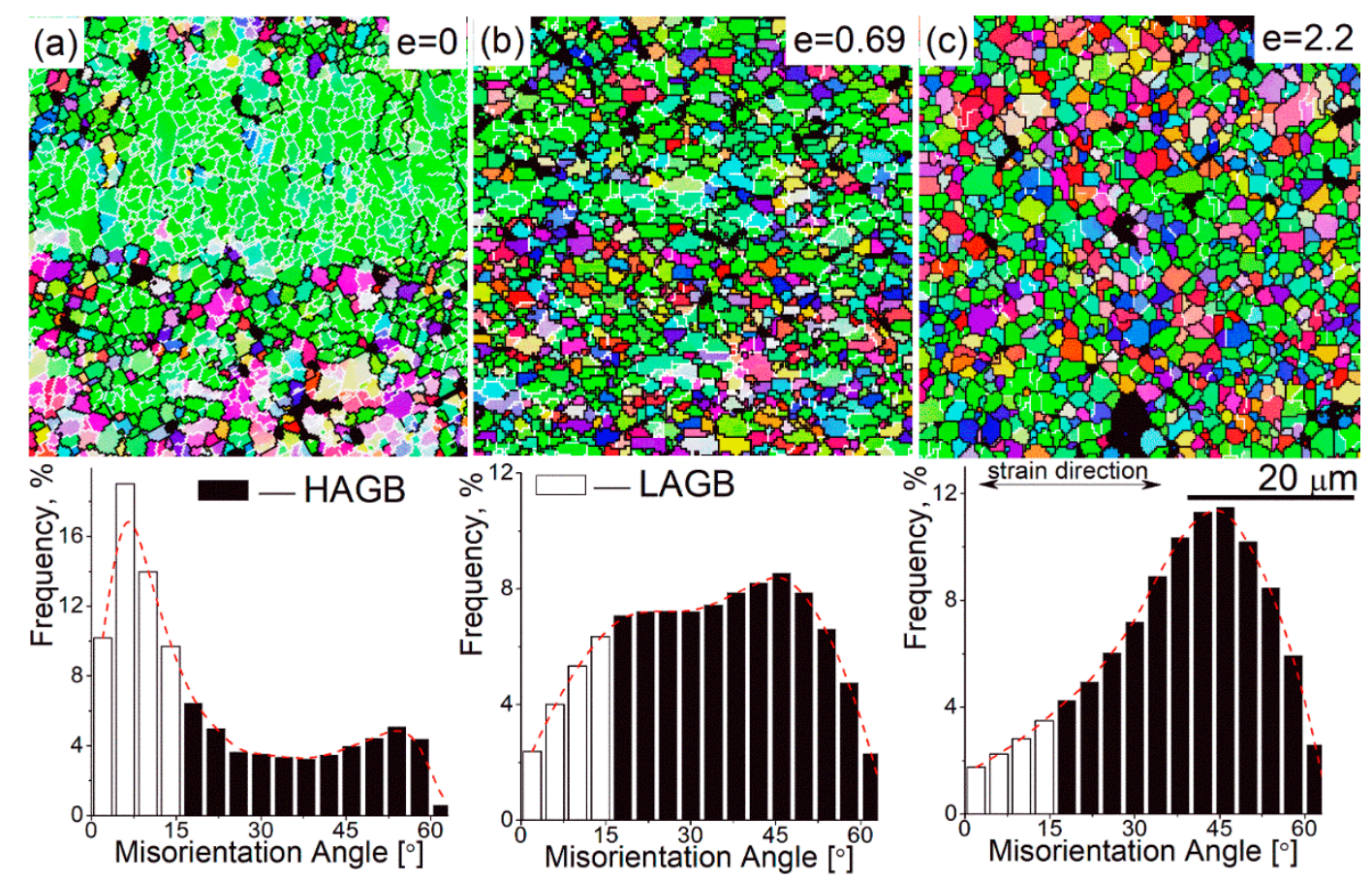

Figure 4. SEM-electron backscatter diffraction (EBSD) grain boundaries maps (the low-angle grain boundaries (LAGBs) are white colored and the high-angle grain boundaries (HAGBs) are black colored in the maps), and the angle misorientation of the samples deformed to $0(\mathbf{a}), 0.69$ (b), 2.2 (c) at $0.02 \mathrm{~s}^{-1}$ and $440{ }^{\circ} \mathrm{C}$. 
The dislocation structure was studied before the start of superplastic deformation and after the deformation with strains of $0.69,1.49$, and 2.2 (Figure 5). The initial microstructure consisted of subgrains and grains with a low amount of dislocations inside them (Figure $5 \mathrm{a}-\mathrm{c}$ ). Many dislocation walls were observed after 0.69 and 1.49 of strain (Figure 5d-f, arrows). After a strain of 2.2 near failure, high-angle grain boundaries were observed, and the grains were almost free of dislocations. The precipitation-depleted zones (PDZ) were identified on both sides of the HAGB boundaries and in triple junctions (Figure $5 \mathrm{~g}-\mathrm{i}$ ). This phenomenon typically associates with the diffusion creep mechanism that can accommodate the grain boundary sliding and be an important independent deformation mechanism [71].
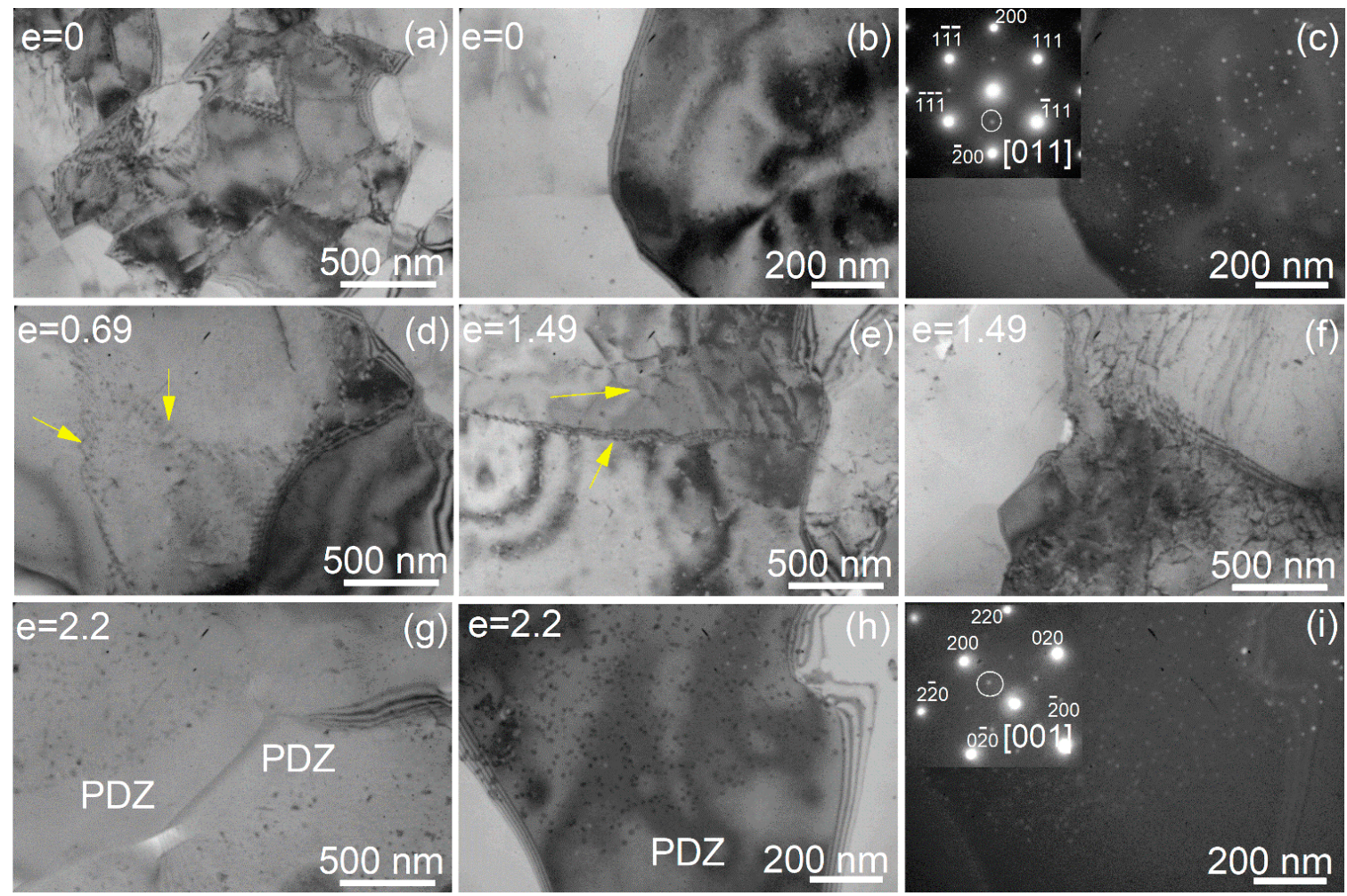

Figure 5. TEM structures after $20 \mathrm{~min}$ of annealing at $440{ }^{\circ} \mathrm{C}(\mathbf{a}-\mathbf{c})$, after strain $0.69(\mathbf{d}), 1.49(\mathbf{e}, \mathbf{f})$, and $2.2(\mathrm{~g}-\mathbf{i})$ at a temperature of $440{ }^{\circ} \mathrm{C}$ and a strain rate of $0.02 \mathrm{~s}^{-1}$; the yellow arrows show the dislocation walls.

High dense distributed $\mathrm{L1}_{2}$-structured nanoprecipitates of the $\mathrm{Al}_{3}(\mathrm{Sc}, \mathrm{Zr})$-phase were observed before the start of the deformation and after failure. Their structural type was unchanged at superplastic deformation, whereas their mean size insignificantly grew from $17 \pm 4 \mathrm{~nm}$ before the start of the deformation to $22 \pm 5 \mathrm{~nm}$ after failure at $\mathrm{e}=2.2$ (Figure 5). Thus, the stable grain structure at superplastic deformation is a result of high density of thermally stable nanoprecipitates of the $\mathrm{L}_{2}-\mathrm{Al}_{3}(\mathrm{Sc}, \mathrm{Zr})$ phase providing the Zener drag.

Superplastic deformation was accompanied by cavitation, which is typical of aluminum-based alloys [18,21,72]. As the grain boundary sliding (GBS) is a dominant superplastic deformation mechanism [71-73], the coarse secondary particles on the grain boundaries are expected to act as nucleation sites for strain-induced cavities [72]. In the studied alloy, the cavities formed near the eutectic particles and far from them (Figure 3c), but the volume fraction of the residual cavities reached only $1.2 \%$ after deformation to failure. This value of residual cavitation is several times lower compared with that of in the AA7475 alloy [71]. Despite the $10 \%$ of $\mathrm{Al}_{3} \mathrm{Ni}$ coarse particles, the residual cavitation was insignificant in the designed alloy. First, a cause of low residual cavitation is a compact near-spherical shape of the $\mathrm{Al}_{3} \mathrm{Ni}$ particles. Second, the local lattice misorientations with increased dislocation density, 
which formed near coarse and hard $\mathrm{Al}_{3} \mathrm{Ni}$ particles, provide a formation of new grains surrounded by HAGB during the superplastic flow [11,45]. It is suggested that low cavitation can be a result of a rapid accommodation of the GBS in a fine-grained structure, including the places near the coarse particles. As it was shown in [46,74], the superplastic properties of the Al-Zn-Mg-Cu-Zr-Sc alloy were also significantly improved due to the presence of the coarse Ni-bearing particles.

Due to its microstructural design, in the presence of the coarse $\mathrm{Al}_{3} \mathrm{Ni}$ particles of eutectic origin and the $\mathrm{L1}_{2}-\mathrm{Al}_{3}(\mathrm{Sc}, \mathrm{Zr})$ nanoprecipitates, the developed alloy exhibits a stable fine-grained structure at superplastic deformation, low residual cavitation, and high strain rate superplasticity up to a strain rate of $1 \mathrm{~s}^{-1}$.

\subsection{Flow Stress Behavior Modeling}

\subsubsection{Arrhenius-Type constitutive hyperbolic Equation model (ACE)}

The flow stress $(\sigma)$ depends on the deformation temperature $(T)$, strain rate $(\dot{\varepsilon})$, and strain $(\varepsilon)$ as follows (Equation (4)) [75],

$$
\sigma=f(T, \dot{\varepsilon}, \varepsilon) .
$$

The Zener-Holloman parameter $(Z)$ in the exponent-type formula is used to describe the relationship between $\mathrm{T}, \dot{\varepsilon}$, and $\varepsilon$ (Equation (5) and (6)) [58,75,76],

$$
\begin{aligned}
& Z=\dot{\varepsilon}\left(\exp { }^{\left(\frac{Q}{R T}\right)}\right) \\
& \dot{\varepsilon}=A f(\sigma)\left(\exp ^{\left(-\frac{Q}{R T}\right)}\right)=\varepsilon^{\prime} \\
& =\left\{\begin{array}{l}
A_{1} \sigma^{n_{1}}\left(\exp ^{\left(-\frac{Q 1}{R T}\right)}\right)-\text { Power law } \\
A_{2}\left(\exp ^{(\beta \sigma)}\right)\left(\exp ^{\left(-\frac{Q 2}{R T}\right)}\right)-\text { Exponential law } \\
A_{3}[\sinh (\alpha \sigma)]^{n_{2}}\left(\exp ^{\left(-\frac{Q 3}{R T}\right)}\right)-\text { Hyperbolic sine law }
\end{array}\right.
\end{aligned}
$$

where

$A_{1,2,3}, \alpha\left(\alpha=\beta / n_{1}\right), \beta, n_{1}, n_{2}$ are the material constants that depend on the effective strain

$Q_{1,2,3}$ are the thermal deformation activation energy in $\mathrm{J} / \mathrm{mol}$

$T$ is the absolute temperature in $\mathrm{K}$

$R$ is the universal gas constant, $8.314 \mathrm{~J} /(\mathrm{mol} \cdot \mathrm{K})$.

Due to their high efficiency in wide ranges of stress levels, the hyperbolic sine law is utilized to construct the proposed constitutive model in this work $[56,58,63]$.

\subsubsection{Determination of the Constitutive Model Constants}

The procedure of determining the constitutive model constants $\left(\alpha, Q_{3}, \ln \left(A_{3}\right)\right.$, and $\left.n_{2}\right)$ is illustrated in detail in $[65,66]$. On the bases of the hyperbolic sin law, the relationship between $\dot{\varepsilon}$, T, and $\sigma$ can be expressed as follows (Equation (7)),

$$
\dot{\varepsilon}=A_{3}[\sinh (\alpha \sigma)]^{n_{2}} \exp ^{\left(-\frac{Q 3}{R T}\right)}
$$

The flow stress can be written as a function in the Zener-Holloman parameter according to the hyperbolic law (Equation (8)).

$$
\sigma=\frac{1}{\alpha} \ln \left\{\left(\frac{\dot{\varepsilon} \exp ^{\left(\frac{Q 3}{R T}\right)}}{A_{3}}\right)^{\frac{1}{n_{2}}}+\left[\left(\frac{\dot{\varepsilon} \exp ^{\left(\frac{Q 3}{R T}\right)}}{A_{3}}\right)^{\frac{2}{n_{2}}}+1\right]^{\frac{1}{2}}\right\}
$$


Figure 6 shows the dependences of the $\alpha$ (Figure 6a), $Q_{3}$ (Figure $6 \mathrm{~b}$ ), $\ln \left(\mathrm{A}_{3}\right)$ (Figure $6 \mathrm{c}$ ), and $\mathrm{n}_{2}$ (Figure 6d) on strain.

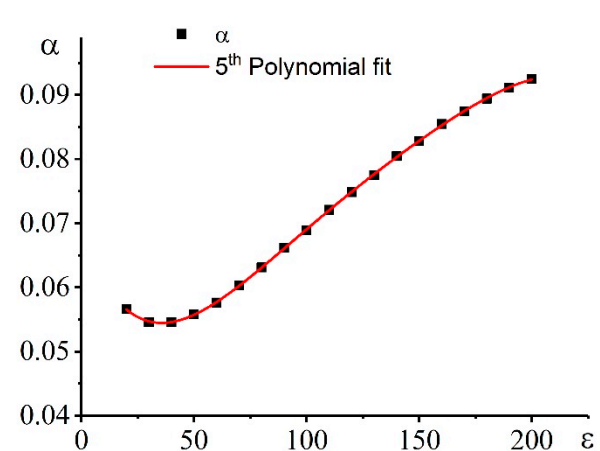

(a)

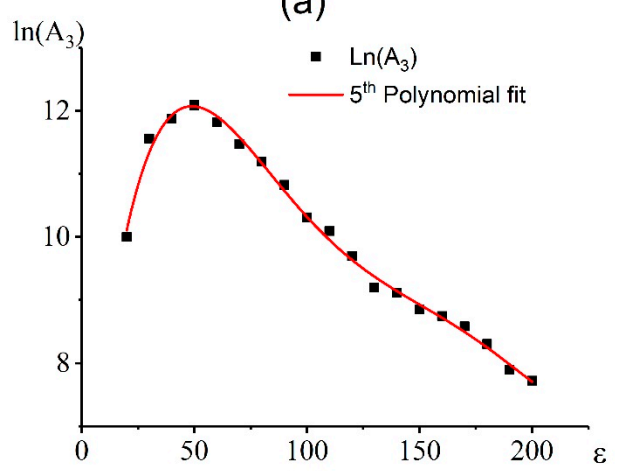

(c)

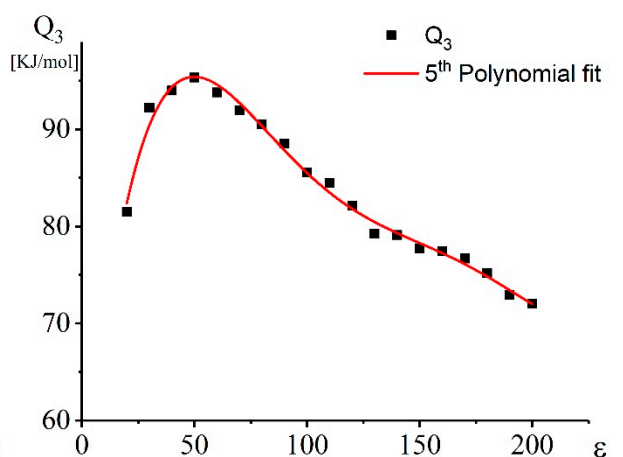

(b) $n_{2}$

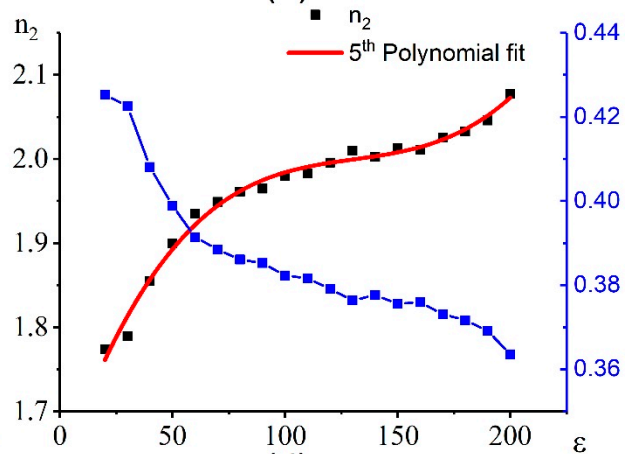

(d)

Figure 6. Dependence of the (a) $\alpha,(\mathbf{b}) \mathrm{Q}_{3},(\mathbf{c}) \ln \left(\mathrm{A}_{3}\right)$, and (d) $\mathrm{n}_{2}$ on strain.

Based on the correlation coefficient $(\mathrm{R})$, the most appropriate polynomial order is the 5th order. The coefficients of the equations for the all parameters are illustrated as follows (Equations (9)- $(12))[65,76]$.

$$
\begin{gathered}
\alpha=a+b(\varepsilon)+c\left(\varepsilon^{2}\right)+d\left(\varepsilon^{3}\right)+e\left(\varepsilon^{4}\right)+f\left(\varepsilon^{5}\right) \\
Q_{3}=a+b(\varepsilon)+c\left(\varepsilon^{2}\right)+d\left(\varepsilon^{3}\right)+e\left(\varepsilon^{4}\right)+f\left(\varepsilon^{5}\right) \\
\operatorname{Ln}\left(A_{3}\right)=a+b(\varepsilon)+c\left(\varepsilon^{2}\right)+d\left(\varepsilon^{3}\right)+e\left(\varepsilon^{4}\right)+f\left(\varepsilon^{5}\right) \\
n_{2}=a+b(\varepsilon)+c\left(\varepsilon^{2}\right)+d\left(\varepsilon^{3}\right)+e\left(\varepsilon^{4}\right)+f\left(\varepsilon^{5}\right)
\end{gathered}
$$

The coefficients $(a, b, c, d, e$, and $f)$ and the $R^{2}$ of the 5 th-order polynomial equation for each material constant are given in Table 1.

Table 1. The calculated coefficients in Equations (9)-(12).

\begin{tabular}{ccccc}
\hline Coefficients & $\boldsymbol{\alpha}$ & $\mathbf{Q}_{3}$ & $\mathbf{L n}\left(\mathbf{A}_{3}\right)$ & $\mathbf{n}_{2}$ \\
\hline $\mathbf{a}$ & 0.06794 & 47.62414 & 4.73584 & 1.62913 \\
$\mathbf{b}$ & $-8.99155 \times 10^{-4}$ & 2.54795 & 0.39416 & 0.00757 \\
$\mathbf{c}$ & $1.92787 \times 10^{-5}$ & -0.0476 & -0.00737 & $-5.09154 \times 10^{-5}$ \\
$\mathbf{d}$ & $-1.49955 \times 10^{-7}$ & $3.81136 \times 10^{-4}$ & $5.83719 \times 10^{-5}$ & $8.17962 \times 10^{-8}$ \\
$\mathbf{e}$ & $5.68411 \times 10^{-10}$ & $-1.42221 \times 10^{-6}$ & $-2.15681 \times 10^{-7}$ & $3.02081 \times 10^{-10}$ \\
$\mathbf{f}$ & $-8.64638 \times 10^{-13}$ & $2.01632 \times 10^{-9}$ & $3.02832 \times 10^{-10}$ & $-5.38008 \times 10^{-13}$ \\
$\mathbf{R}^{\mathbf{2}}$ & 0.999 & 0.991 & 0.995 & 0.983 \\
\hline
\end{tabular}


Once the material constants are evaluated via Equations (9)-(12), the flow stress at an effective strain rate is predicted using Equation (8). Figure 7 shows the stress-strain dependence at different temperatures and strain rates of the investigated alloy.

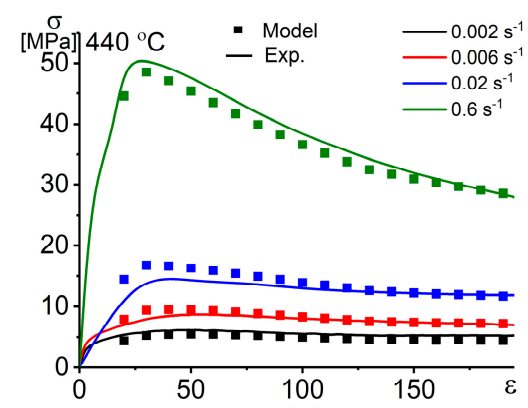

(a)

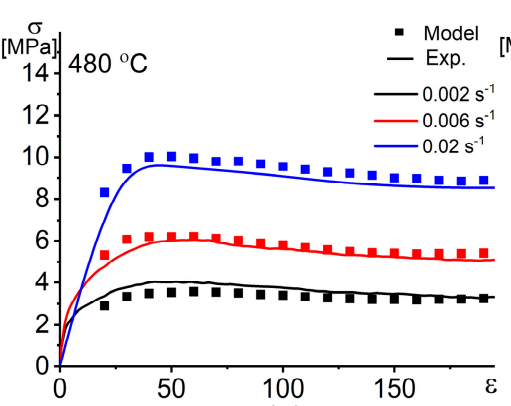

(b)

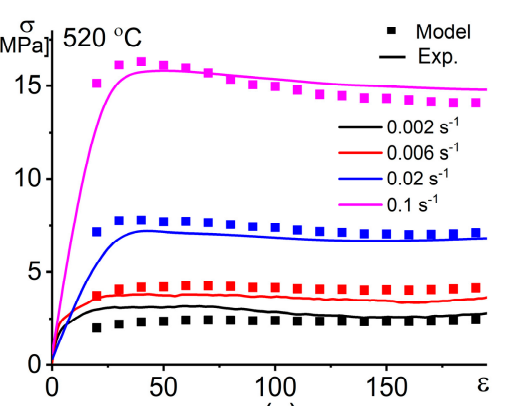

(c)

Figure 7. Dependences of the experimental and the predicted by the Arrhenius-type constitutive hyperbolic equation (ACE) model stresses vs. strain at different strain rates and temperatures of (a) $440{ }^{\circ} \mathrm{C}$, (b) $480{ }^{\circ} \mathrm{C}$, and (c) $520^{\circ} \mathrm{C}$.

\subsubsection{Artificial Neural Network Model (ANN)}

The ANN is widely used for modeling and simulating the flow behavior of metallic materials due to its simplicity and fast response. Thus, the main aim here is to compare the predictability of the mechanical behavior of the studied alloy using the ANN and the classical approach based on the constitutive equations of the Arrhenius type. In this work, a three-layer network with the backpropagation algorithm was used to model the flow stress of the investigated alloy. The deformation temperature, the deformation strain rate, and strain are chosen as the inputs, and the flow stress is set as the output in the model. The ANN architecture is schematically illustrated in Figure 8. The setting of other training parameters for the neural network is listed in Table 2 according to $[65,66]$.

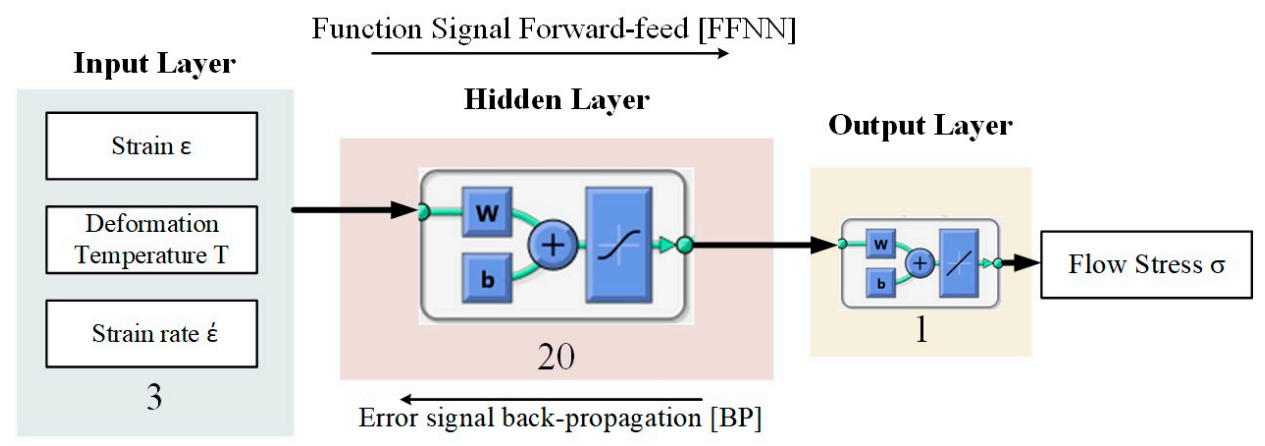

Figure 8. Schematic illustration of the artificial neural network (ANN) architecture of the used network.

Table 2. Settings of the training parameters for the used neural network.

\begin{tabular}{|c|c|}
\hline Parameters & Contents \\
\hline Network & Backpropagation Network (BP) \\
\hline Function & TrainLM \\
\hline Transfer function of output layer & Liner (purelin) \\
\hline Transfer function of hidden layer & Tan-sigmoid \\
\hline Training epoch & 8000 \\
\hline Goal & $1 \times 10^{-6}$ \\
\hline Performance function & MSE \\
\hline
\end{tabular}

Figure 9 shows the correlation between the experimental flow stress and the modeled flow stress obtained by the constitutive model and the ANN model at different strain rates and temperatures. 
The correlation between the experimental flow stress and the modeled flow stress via both ACE and ANN models is shown in Figure 10. After fitting and approximation, the values of the performance indicators R, AARE (\%), and RMSE for the ACE model are 0.992, 6.0\%, and 0.95, respectively. These values for the ANN model are 0.999, 2.5\%, and 0.45, respectively. Both the Arrhenius-type constitutive model (ACE) and the artificial neural network (ANN) exhibit good workability in modeling and predicting the flow stress of the investigated alloy; however, the ANN is more accurate than the ACE.

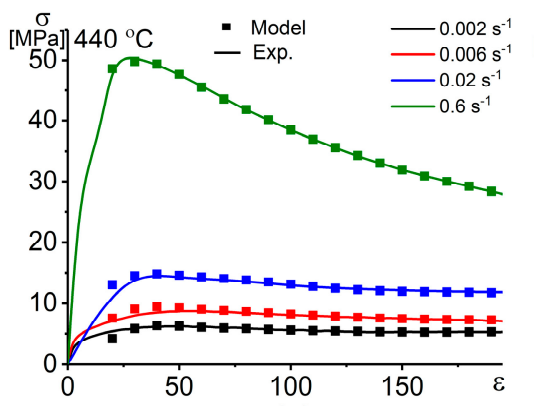

(a)

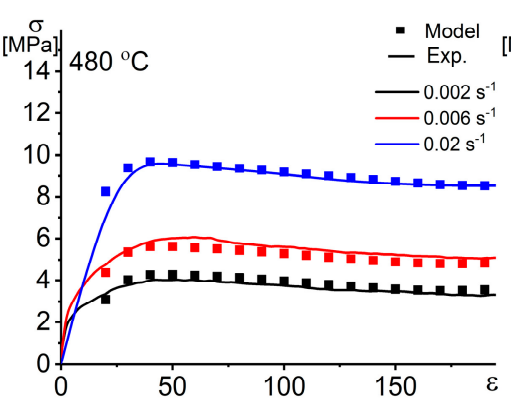

(b)

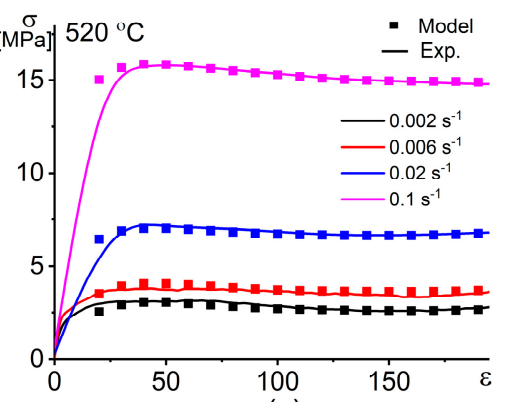

(c)

Figure 9. Dependences of the experimental and the predicted in the ANN model stresses vs. strain at different strain rates and temperatures of (a) $440{ }^{\circ} \mathrm{C}$, (b) $480{ }^{\circ} \mathrm{C}$, and (c) $520{ }^{\circ} \mathrm{C}$.

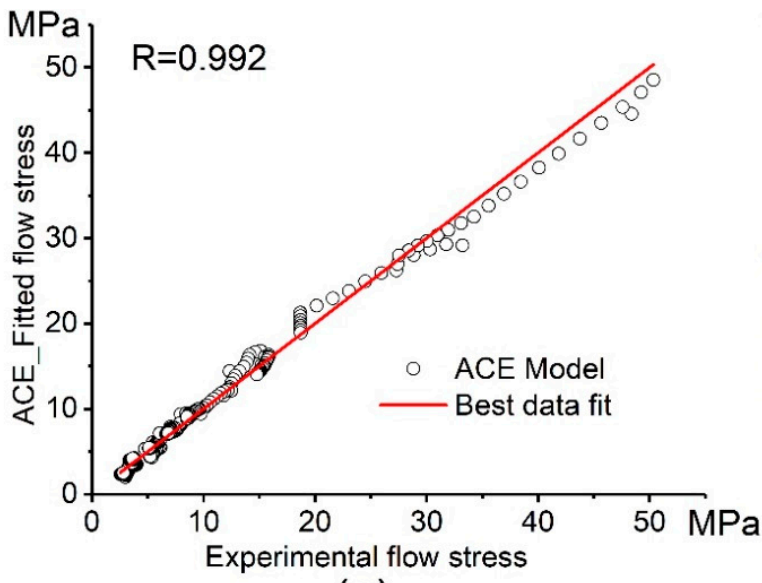

(a)

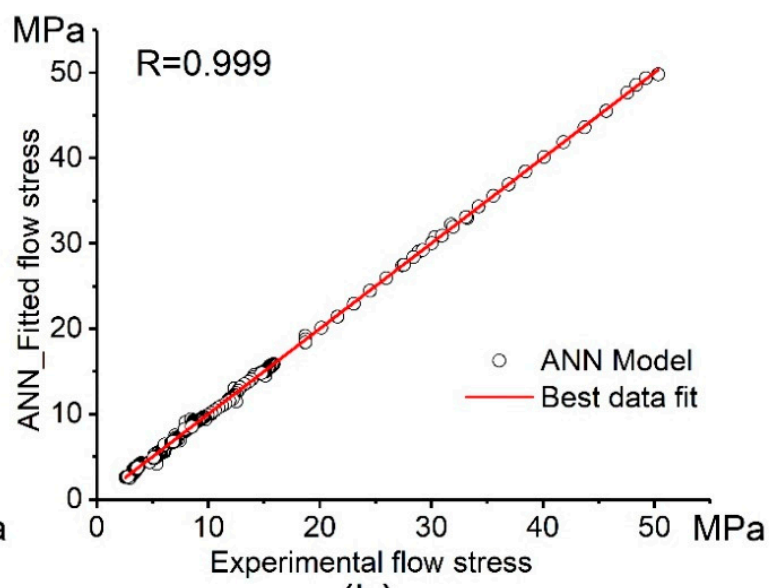

(b)

Figure 10. Correlation between the experimental and the modeled flow stress obtained by the (a) Constitutive model and (b) ANN model.

\subsubsection{Models Verification}

To evaluate the quality and the performance of the constructed models, more experimental results obtained from the isothermal tensile tests at $440{ }^{\circ} \mathrm{C}, 0.01 \mathrm{~s}^{-1}$, and $0.1 \mathrm{~s}^{-1}$ were used to test both models (these conditions are not included in the input conditions for constructing both models). Figure 11 shows the comparison and correlation between the experimental flow stress and the predicted flow stress for both models. After the prediction of unmodeled conditions, the values of the performance indicators R, AARE (\%), and RMSE for the ACE model are 0.94, 1.4\%, and 0.5, respectively, whereas these values are $0.98,1.1 \%$, and 0.4 for the ANN model, respectively. The results revealed excellent efficiency of the constructed models for high and low strain rates. 


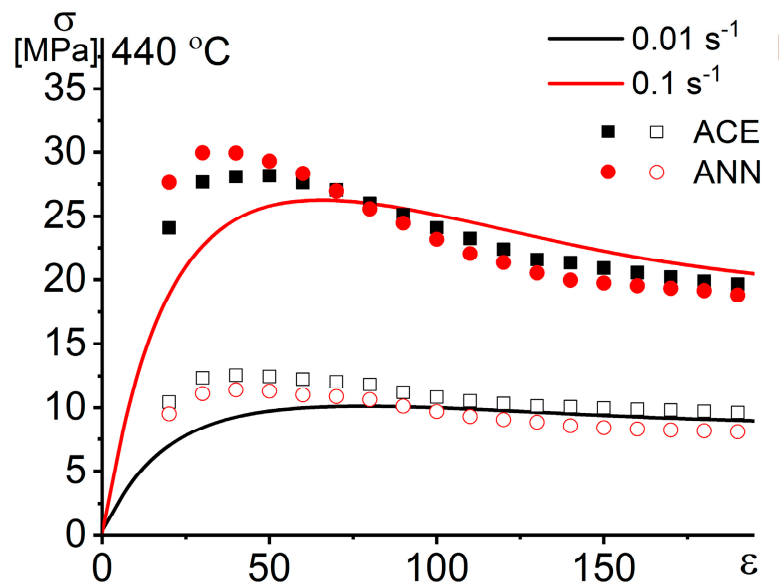

(a)

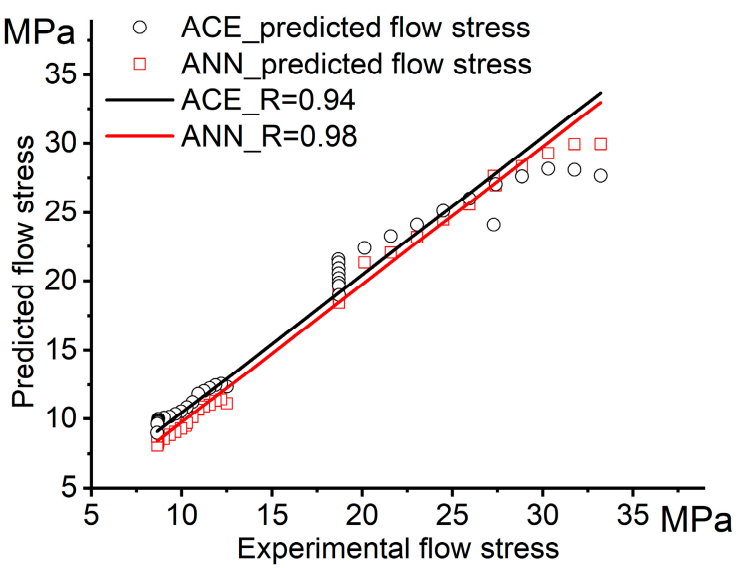

(b)

Figure 11. (a) Dependence and (b) correlation of the experimental and the predicted flow stress obtained by the constitutive model (CE) and the ANN model vs. strain.

Figure 11 demonstrates a minor difference between the predictability of the flow stress using a classical approach based on the Arrhenius type constitutive equation and the Artificial neural network. Thus, the ANN can be used for modeling of the superplastic flow behavior as a simple modeling approach.

\section{Conclusions}

The superplastic deformation behavior and strain-induced microstructural evolution of the novel Al-3.8\%Zn-4.2\%Mg-3.6\%Ni-0.19\%Zr-0.06wt.\%Sc alloy were studied by optical, scanning, and transmission electron microscopy techniques. Sheets were processed by a simple thermomechanical treatment. The mathematical models of the stress-strain behavior were developed. The following conclusions are summarized.

1. Before the start of superplastic deformation in a temperature range of 400 to $520{ }^{\circ} \mathrm{C}$ $\left(0.86-0.96 \mathrm{~T}_{\mathrm{i} . \mathrm{m}}\right)$, the microstructure of the cross-thickness sheet section consists of un-recrystallized banded grains of $2.8 \mu \mathrm{m}$ thickness, $\sim 10 \%$ of the $\mathrm{Al}_{3} \mathrm{Ni}$ coarse particles of eutectic origin of $0.8 \mu \mathrm{m}$ mean size, and nanoprecipitates of $\mathrm{L}_{2}-\mathrm{Al}_{3}(\mathrm{Sc}, \mathrm{Zr})$ phase with a mean size of $\sim 20 \mathrm{~nm}$.

2. The alloy demonstrates superplasticity in a strain rate range from traditionally low $0.002 \mathrm{~s}^{-1}$ to an extremely high strain rate of $1 \mathrm{~s}^{-1}$ in a temperature range of 400 to $520^{\circ} \mathrm{C}$ with elongation-to-failure of $400-800 \%$ and strain rate sensitivity index $m>0.3$.

3. The analyses of the strain-induced microstructural evolution at an optimal superplastic temperature of $440^{\circ} \mathrm{C}$ and a strain rate of $0.02 \mathrm{~s}^{-1}$ revealed a formation of dislocation walls, an increasing of the high angle grain boundaries fraction at low strains, low residual cavitation $<2 \%$, weak dynamic grain growth, and a stable size and structure of the $\mathrm{L1}_{2}-\mathrm{Al}_{3}(\mathrm{Sc}, \mathrm{Zr})$ nanoprecipitates. The formation of precipitate-depleted zones on the grain boundaries and triple junctions, which suggested a diffusional creep deformation mechanism, was revealed.

4. Due to its microstructural design, in the presence of the coarse $\mathrm{Al}_{3} \mathrm{Ni}$ particles provided PSN, and the $\mathrm{L1}_{2}-\mathrm{Al}_{3}(\mathrm{Sc}, \mathrm{Zr})$ nanoprecipitates provided grain size stabilization via the Zener pinning effect, the designed alloy exhibits a stable fine-grained structure, low residual cavitation at superplastic flow and, as a result, high strain rate superplasticity.

5. After both fitting and the prediction of unmodeled conditions, the mathematical Arrhenius-type model and the artificial neural network model exhibited good workability. The average absolute relative error between the experimental and the predicted flow stress did not exceed $1.5 \%$ for both models. Therefore, both models efficiently approximate and predict the flow behavior of the alloy under superplastic deformation at high and low strain rates. 
6. Extraordinarily high strain rate superplasticity of the alloy processed by a simple thermomechanical treatment as well as low scandium content in this alloy makes the novel alloy an attractive material for superplastic forming. Further experiments should be focused on determining the dominant deformation mechanism of high strain rate superplasticity. A role of each microstructural parameter in the deformation behavior needs to be identified. It helps to develop new aluminum-based alloys with high strain rate superplasticity.

Author Contributions: Conceptualization A.M., methodology, O.Y. and M.S.; investigation, O.Y. and M.N.S; modeling experiments, A.O.M., writing-original draft preparation, O.Y., A.O.M. and A.M.; writing-review and editing, A.M.; supervision, A.M. All authors have read and agreed to the published version of the manuscript.

Funding: The study was financially supported by the Russian Science Foundation (grant No. 19-79-00353).

Acknowledgments: The authors would like to thank V. Cheverikin for EBSD study and E. Bazanova for critical reading of the manuscript and helpful recommendations.

Conflicts of Interest: The authors declare no conflicts of interest.

\section{References}

1. Chokshi, A.H.; Mukherjee, A.K.; Langdon, T.G. Superplasticity in advanced materials. Mater. Sci. Eng. R 1993, 10, 237-274. [CrossRef]

2. Davies, G.J.; Edington, J.W.; Cutler, C.P.; Padmanabhan, K.A. Superplasticity: A review. J. Mater. Sci. 1970, 5, 1091-1102. [CrossRef]

3. Edington, J.W.; Melton, K.N.; Cutler, C.P. Superplasticity; Elsevier: Amsterdam, The Netherlands, 1976; Volume 21, ISBN 9283505255.

4. Kawasaki, M.; Langdon, T.G. Review: Achieving superplasticity in metals processed by high-pressure torsion. J. Mater. Sci. 2014, 49, 6487-6496. [CrossRef]

5. Langdon, T.G. Seventy-five years of superplasticity: Historic developments and new opportunities. J. Mater. Sci. 2009, 44, 5998-6010. [CrossRef]

6. Novikov, I.I.; Portnoj, V.K. Superplastizität von Legierungen; VEB Deutscher Verlag fur Grundstoffindustrie: Leipzig, Germayny, 1985.

7. Perez-Prado, M.T.; Kassner, M.E. Superplasticity. In Fundamentals of Creep in Metals and Alloys: Third Edition; Butterworth-Heinemann: Oxford, UK, 2015; ISBN 9780080994277.

8. Nieh, T.G.; Wadsworth, J.; Sherby, O.D. Superplasticity in Metals and Ceramics; Cambridge University Press: Cambridge, UK, 1997; ISBN 9780521561051.

9. Sieniawski, J.; Motyka, M. Superplasticity in titanium alloys. J. Achiev. Mater. Manuf. Eng. 2007, 24, 123-130.

10. Barnes, A.J. Superplastic forming 40 years and still growing. J. Mater. Eng. Perform. 2007, 16, 440-454. [CrossRef]

11. Wang, X.G.; Li, Q.S.; Wu, R.R.; Zhang, X.Y.; Ma, L. A Review on Superplastic Formation Behavior of Al Alloys. Adv. Mater. Sci. Eng. 2018, 2018, 1687-8434. [CrossRef]

12. Ridley, N. Metals for superplastic forming. In Superplastic Forming of Advanced Metallic Materials: Methods and Applications; Woodhead Publishing: Amsterdam, The Netherlands, 2011; pp. 3-33. ISBN 9781845697532.

13. Hsiao, I.C.; Huang, J.C. Deformation mechanisms during low- and high-temperature superplasticity in 5083 Al-Mg alloy. Metall. Mater. Trans. A Phys. Metall. Mater. Sci. 2002, 33, 1373-1384. [CrossRef]

14. Yogesha, B.; Divya, H.V.; Bhattacharya, S.S. Superplasticity and superplastic tensile behaviour of AA5083. Adv. Mater. Res. 2014, 902, 24-28. [CrossRef]

15. Johannes, L.B.; Charit, I.; Mishra, R.S.; Verma, R. Enhanced superplasticity through friction stir processing in continuous cast AA5083 aluminum. Mater. Sci. Eng. A 2007, 464, 351-357. [CrossRef]

16. Kulas, M.A.; Green, W.P.; Pettengill, E.C.; Krajewski, P.E.; Taleff, E.M. Superplastic failure mechanisms and ductility of AA5083. In Advances in Superplasticity and Superplastic Forming; TMS (The Minerals, Metals \&Materials Society): Warrendale, PA, USA, 2004; pp. 127-138.

17. Sotoudeh, K.; Ridley, N.; Humphreys, F.J.; Bate, P.S. Superplasticity and microstructural evolution in aluminium alloys. Materialwissenschaft und Werkstofftechnik 2012, 43, 794-798. [CrossRef]

18. Ma, Z.Y.; Mishra, R.S. Cavitation in superplastic $7075 \mathrm{Al}$ alloys prepared via friction stir processing. Acta Mater. 2003, 51, 3551-3569. [CrossRef] 
19. Campbell, J. Cavitation during superplastic forming. Materials (Basel) 2011, 4, 1271-1286. [CrossRef] [PubMed]

20. Yoshida, H.; Kumagai, M.; Matsuda, S.I. Superplasticity of Aluminium Alloys. Sumitomo Light Met. Tech. Rep. 1990, 31, 41-46.

21. Chen, C.L.; Tan, M.J. Cavity growth and filament formation of superplastically deformed Al 7475 Alloy. Mater. Sci. Eng. A 2001, 298, 235-244. [CrossRef]

22. Chen, C.L.; Tan, M.J. Effect of grain boundary character distribution (GBCD) on the cavitation behaviour during superplastic deformation of Al 7475. Mater. Sci. Eng. A 2002, 338, 243-252. [CrossRef]

23. Shin, D.H.; Park, K.T. Directional cavity stringer formation in a superplastic $7075 \mathrm{Al}$ alloy. Mater. Sci. Eng. A 1999, 268, 55-62. [CrossRef]

24. Valiev, R.Z.; Salimonenko, D.A.; Tsenev, N.K.; Berbon, P.B.; Langdon, T.G. Observations of high strain rate superplasticity in commercial aluminum alloys with ultrafine grain sizes. Scr. Mater. 1997, 37, 1945-1950. [CrossRef]

25. Kawasaki, M.; Langdon, T.G. Principles of superplasticity in ultrafine-grained materials. J. Mater. Sci. 2007, 42, 1782-1796. [CrossRef]

26. Langdon, T.G. Mechanics of Materials Achieving superplasticity in ultrafine-grained metals. Mech. Mater. 2013, 67, 2-8. [CrossRef]

27. Liu, F.C.; Ma, Z.Y. Superplasticity governed by effective grain size and its distribution in fine-grained aluminum alloys. Mater. Sci. Eng. A 2011, 530, 548-558. [CrossRef]

28. Blandin, J.J. Superplasticity of metallic alloys: Some current findings and open questions. Mater. Sci. Forum 2016, 838, 13-22. [CrossRef]

29. Ma, Z.Y.; Mishra, R.S.; Mahoney, M.W. Superplastic deformation behaviour of friction stir processed $7075 \mathrm{Al}$ alloy. Acta Mater. 2002, 50, 4419-4430. [CrossRef]

30. Kawasaki, M.; Langdon, T.G. Developing superplasticity in ultrafine-grained metals. Acta Phys. Pol. A 2015, 128, 470-478. [CrossRef]

31. Kawasaki, M.; Langdon, T.G. Description of the superplastic flow process by deformation mechanism maps in ultrafine-grained materials. Mater. Sci. Forum 2016, 838, 51-58. [CrossRef]

32. Xu, C.; Furukawa, M.; Horita, Z.; Langdon, T.G. Severe plastic deformation as a processing tool for developing superplastic metals. J. Alloys Compd. 2004, 378, 27-34. [CrossRef]

33. Xu, C.; Horite, Z.; Furukawa, M.; Langdon, T.G. Using equal-channel angular pressing for the production of superplastic aluminum and magnesium alloys. J. Mater. Eng. Perform. 2004, 13, 683-690. [CrossRef]

34. Málek, P.; Poková, M.Š.; Cieslar, M. High temperature deformation of twin-roll cast Al-Mn-based alloys after equal channel angular pressing. Materials (Basel) 2015, 8, 7650-7662. [CrossRef]

35. Jiang, D.; Liu, R.; Wang, C.; Wang, Z.; Imai, T. Microstructure and superplasticity of an Al-Zn-Mg-Cu alloy. J. Mater. Sci. 1999, 34, 3363-3366. [CrossRef]

36. Humphreys, F.J. The nucleation of recrystallization at second phase particles in deformed aluminium. Acta Metall. 1977, 25, 1323-1344. [CrossRef]

37. Humphreys, F.J.; Hatherly, M. Recrystallization of Two-Phase Alloys. In Recrystallization and Related Annealing Phenomena; Elsevier: Amsterdam, The Netherlands, 2004; pp. 285-319. [CrossRef]

38. Troeger, L.P.; Starke, E.A. Particle-stimulated nucleation of recrystallization for grain-size control and superplasticity in an Al-Mg-Si-Cu alloy. Mater. Sci. Eng. A 2000, 293, 19-29. [CrossRef]

39. Xu, W.; Ferry, M.; Cairney, J.M.; Humphreys, F.J. Three-dimensional investigation of particle-stimulated nucleation in a nickel alloy. Acta Mater. 2007, 55, 5157-5167. [CrossRef]

40. Robson, J.D.; Henry, D.T.; Davis, B. Particle effects on recrystallization in magnesium-manganese alloys: Particle-stimulated nucleation. Acta Mater. 2009, 57, 2739-2747. [CrossRef]

41. Wang, N.; Ji, Y.; Wang, Y.; Wen, Y.; Chen, L.Q. Two modes of grain boundary pinning by coherent precipitates. Acta Mater. 2017, 135, 226-232. [CrossRef]

42. Huang, K.; Logé, R.E. Zener Pinning. In Reference Module in Materials Science and Materials Engineering; Elsevier: Amsterdam, The Netherlands, 2016; pp. 1-8.

43. Markushev, M.V. On the principles of the deformation methods of aluminum-alloys grain refinement to ultrafine size: I. Fine-grained alloys. Phys. Met. Metallogr. 2009, 108, 43-49. [CrossRef]

44. Hyde, K.B.; Bate, P.S. Dynamic grain growth in Al-6Ni: Modelling and experiments. Acta Mater. 2005, 53, 4313-4321. [CrossRef] 
45. Mikhaylovskaya, A.V.; Kotov, A.D.; Pozdniakov, A.V.; Portnoy, V.K. A high-strength aluminium-based alloy with advanced superplasticity. J. Alloys Compd. 2014, 599, 139-144. [CrossRef]

46. Kotov, A.D.; Mikhaylovskaya, A.V.; Kishchik, M.S.; Tsarkov, A.A.; Aksenov, S.A.; Portnoy, V.K. Superplasticity of high-strength Al-based alloys produced by thermomechanical treatment. J. Alloys Compd. 2016, 688, 336-344. [CrossRef]

47. Mikhaylovskaya, A.V.; Mochugovskiy, A.G.; Kotov, A.D.; Yakovtseva, O.A.; Gorshenkov, M.V.; Portnoy, V.K. Superplasticity of clad aluminium alloy. J. Mater. Process. Technol. 2017, 243, 355-364. [CrossRef]

48. Barkov, R.Y.; Pozdniakov, A.V.; Tkachuk, E.; Zolotorevskiy, V.S. Effect of Y on microstructure and mechanical properties of Al-Mg-Mn-Zr-Sc alloy with low Sc content. Mater. Lett. 2018, 217, 135-138. [CrossRef]

49. Filatov, Y.A.; Yelagin, V.I.; Zakharov, V.V. New Al-Mg-Sc alloys. Mater. Sci. Eng. A 2000, 280, 97-101. [CrossRef]

50. Mikhaylovskaya, A.V.; Yakovtseva, O.A.; Cheverikin, V.V.; Kotov, A.D.; Portnoy, V.K. Superplastic behaviour of Al-Mg-Zn-Zr-Sc-based alloys at high strain rates. Mater. Sci. Eng. A 2016, 659, 225-233. [CrossRef]

51. Loginova, I.; Khalil, A.; Pozdniakov, A.; Solonin, A.; Zolotorevskiy, V. Effect of pulse laser welding parameters and filler metal on microstructure and mechanical properties of Al-4.7Mg-0.32Mn-0.21Sc-0.1Zr alloy. Metals (Basel) 2017, 7, 564. [CrossRef]

52. Zhao, Z.D.; Xu, X.F.; Tong, G.Q.; Zhu, S.F.; Huang, S.D.; Cao, Y. Optimization of pressure cycle for superplastic forming of 5083 aluminum alloy shell. Cailiao Kexue yu Gongyi/Mater. Sci. Technol. 2008, 16, 228-231.

53. Bonet, J.; Gil, A.; Wood, R.D.; Said, R.; Curtis, R. V Simulating superplastic forming. Comput. Methods Appl. Mech. Eng. 2006, 195, 6580-6603. [CrossRef]

54. Vasin, R.A.; Enikeev, F.U.; Tokuda, M.; Safiullin, R.V. Mathematical modelling of the superplastic forming of a long rectangular sheet. Int. J. Non-Linear Mech. 2003, 38, 799-807. [CrossRef]

55. Giuliano, G. Mathematical modelling of superplastic metal sheet forming processes. In Superplastic Forming of Advanced Metallic Materials; Woodhead Publishing: Amsterdam, The Netherlands, 2011.

56. Luo, L.; Liu, Z.; Bai, S.; Zhao, J.; Zeng, D.; Wang, J.; Cao, J.; Hu, Y. Hot Deformation Behavior Considering Strain Effects and Recrystallization Mechanism of an Al-Zn-Mg-Cu Alloy. Metals (Basel) 2020, 13, 1743. [CrossRef]

57. Zhang, H.; Wen, W.; Cui, H.; Xu, Y. A modified Zerilli-Armstrong model for alloy IC10 over a wide range of temperatures and strain rates. Mater. Sci. Eng. A 2009, 527, 328-333. [CrossRef]

58. Mosleh, A.O.; Mikhaylovskaya, A.V.; Kotov, A.D.; Portnoy, V.K. Arrhenius-Type Constitutive Equation Model of Superplastic Deformation Behaviour of Different Titanium Based Alloys. Defect Diffus. Forum 2018, 385, 48-52. [CrossRef]

59. He, Z.; Wang, Z.; Lin, P. A Comparative Study on Arrhenius and Johnson-Cook Constitutive Models for High-Temperature Deformation of Ti2AlNb-Based Alloys. Metals 2019, 9, 123. [CrossRef]

60. Chen, X.; Liao, Q.; Niu, Y.; Jia, W.; Le, Q.; Cheng, C.; Yu, F.; Cui, J. A constitutive relation of AZ80 magnesium alloy during hot deformation based on Arrhenius and Johnson-Cook model. J. Mater. Res. Technol. 2019, 8, 1859-1869. [CrossRef]

61. Wang, H.; Zhang, Z.; Zhai, R.; Ma, R.; Zhao, J. New method to develop High temperature constitutive model of metal based on the Arrhenius-type model. Mater. Today Commun. 2020, 24, 101000. [CrossRef]

62. Huang, C.; Jia, X.; Zhang, Z. A Modified Back Propagation Artificial Neural Network Model Based on Genetic Algorithm to Predict the Flow Behavior of 5754 Aluminum Alloy. Materials 2018, 11, 855. [CrossRef] [PubMed]

63. Bahrami, A.; Anijdan, S.H.M.; Hosseini, H.R.M.; Shafyei, A.; Narimani, R. Effective parameters modeling in compression of an austenitic stainless steel using artificial neural network. Comput. Mater. Sci. 2005, 34, 335-341. [CrossRef]

64. Khosravania, M.R.; Nasiri, S.; Weinber, K. Prediction of fracture in sandwich-structured composite joints using CBR approach. Procedia Struct. Integr. 2018, 13, 168-173. [CrossRef]

65. Mosleh, A.O.; Mikhaylovskaya, A.V.; Kotov, A.D.; Kwame, J.S. Experimental, modelling and simulation of an approach for optimizing the superplastic forming of Ti-6\%Al-4\%V titanium alloy. J. Manuf. Process. 2019, 45, 262-272. [CrossRef]

66. Mosleh, A.; Mikhaylovskaya, A.; Kotov, A.; Pourcelot, T.; Aksenov, S.; Kwame, J.; Portnoy, V. Modelling of the Superplastic Deformation of the Near- $\alpha$ Titanium Alloy (Ti-2.5Al-1.8Mn) Using Arrhenius-Type Constitutive Model and Artificial Neural Network. Metals (Basel) 2017, 7, 568. [CrossRef] 
67. Lin, Y.C.; Chen, M.-S.; Zhong, J. Constitutive modeling for elevated temperature flow behavior of $42 \mathrm{CrMo}$ steel. Comput. Mater. Sci. 2008, 42, 470-477.

68. Bodunrin, M.O. Flow stress prediction using hyperbolic-sine Arrhenius constants optimised by simple generalised reduced gradient refinement. J. Mater. Res. Technol. 2019, 9, 2376-2386. [CrossRef]

69. Mohamed, F.A. Micrograin Superplasticity: Characteristics and Utilization. Materials (Basel) 2011, 4, 1194-1223. [CrossRef]

70. Bate, P. The effect of deformation on grain growth in Zener pinned systems. Acta Mater. 2001, 49, $1453-1461$. [CrossRef]

71. Mikhaylovskaya, A.V.; Yakovtseva, O.A.; Sitkina, M.N.; Kotov, A.D.; Irzhak, A.V.; Krymskiy, S.V.; Portnoy, V.K. Comparison between superplastic deformation mechanisms at primary and steady stages of the fine grain AA7475 aluminium alloy. Mater. Sci. Eng. A 2018, 718, 277-286. [CrossRef]

72. Blandin, J.J.; Hong, B.; Varloteaux, A.; Suery, M.; L'Esperance, G. Effect of the nature of grain boundary regions on cavitation of a superplastically deformed aluminium alloy. Acta Mater. 1996, 44, 2317-2326. [CrossRef]

73. Zhang, S.Y.; Wang, C.; Zhao, L.Q.; Ma, P.K.; Song, J.W.; Xu, J.; Cheng, X.M.; Wang, H.Y. Superplastic deformation behavior of rolled Mg-8Al-2Sn and Mg-8Al-1Sn-1Zn alloys at high temperatures. Materials (Basel) 2020, 13, 1074. [CrossRef] [PubMed]

74. Kotov, A.D.; Mikhaylovskaya, A.V.; Borisov, A.A.; Yakovtseva, O.A.; Portnoy, V.K. High-strain-rate superplasticity of the $\mathrm{Al}-\mathrm{Zn}-\mathrm{Mg}-\mathrm{Cu}$ alloys with Fe and $\mathrm{Ni}$ additions. Phys. Met. Metallogr. 2017, 118, 913-921. [CrossRef]

75. Sellars, C.M.; McTegart, W.J. On the mechanism of hot deformation. Acta Metall. 1966, 14, 1136-1138. [CrossRef]

76. Zener, C.; Hollomon, J.H. Effect of strain rate upon plastic flow of steel. J. Appl. Phys. 1944, 15, 22-32. [CrossRef]

(C) 2020 by the authors. Licensee MDPI, Basel, Switzerland. This article is an open access article distributed under the terms and conditions of the Creative Commons Attribution (CC BY) license (http://creativecommons.org/licenses/by/4.0/). 